\title{
A (IN)ADEQUAÇÃO DA POLÍTICA TRIBUTÁRIA ADOTADA PARA 0 DESENVOLVIMENTO SUSTENTÁVEL DA REGIÃO AMAZÔNICA
}

\author{
THE (IN) ADEQUACY OF THE TAX POLICY ADOPTED FOR THE \\ SUSTAINABLE DEVELOPMENT OF THE AMAZON REGION
}

\section{Luciano Costa Miguel ${ }^{1}$ Romeu Faria Thomé da Silva²}

1 Doutorando e Mestre em Direito Ambiental pela Escola Superior Dom Helder Câmara. Professor da Dom Helder Câmara. Procurador da Fazenda Nacional. E-mail: lucianocmiguel@hotmail.com

2 Pós-Doutor em Direito Ambiental pela Université Laval, Canadá. Doutor em Direito pela PUC/MG. Mestre em Direito pela UFMG. Especialista em Direito Ambiental pela Université de Genève, Suíça. Professor permanente do Mestrado e do Doutorado em Direito Ambiental e Desenvolvimento Sustentável da Escola Superior Dom Helder Câmara. E-mail: romeuprof@hotmail.com

RESUMO: Este trabalho visa realizar análises dos instrumentos tributários implementados na Amazônia, considerando, desenvolvimento socioeconômico, preservação e relevância ambiental e geopolítica. Objetiva-se verificar se políticas públicas fiscais aplicadas para desenvolver a região, por meio da atual configuração dos incentivos da Zona Franca de Manaus, alíquotas e isenções do Imposto sobre a Propriedade de Veículos Automotores e da não instituição do Imposto sobre Circulação de Mercadorias e Prestação de Serviços Ecológico, encontram-se em consonância com os direitos socioambientais. Conclui-se que a política tributária é omissa na dimensão ambiental, pouco contribuindo para redução dos índices de desmatamento e para o desenvolvimento regional.

Palavras-chave: Instrumentos tributários. Região Amazônica. Desenvolvimento Sustentável. Políticas públicas

\begin{abstract}
This work aims to carry out analyzes of the tax instruments implemented in the Amazon, considering socio-economic development, preservation and environmental and geopolitical relevance. The objective is to verify whether public fiscal policies applied to develop the region, through the current configuration of the Manaus Free Trade Zone incentives, rates and exemptions from the Motor Vehicle Property Tax and the non-imposition of the Tax on the Circulation of Goods and Installment Ecological Services, are in line with socio-environmental rights. It is concluded that the tax policy is silent on the environmental dimension, contributing little to reducing deforestation rates and regional development.
\end{abstract}

Keywords: Tax instruments. Amazon Region. Sustainable Development. Public policy.

Sumário: Introdução - 1 Os benefícios ambientais e a necessidade geopolítica de uma política tributária ambiental para a Região Amazônica - 2 A ZFM como Instrumento de Política Tributárias - 3 O ICMS Ecológico no Estado do Amazonas - 4 O IPVA no Estado do Amazonas - Considerações Finais - Referências

\section{INTRODUÇÃO}

A questão da proteção da região amazônica ganha contornos complexos ao se considerar que se trata de um espaço dotado de um bioma altamente diversificado e transnacional, povoado por uma multiplicidade cultural e socioeconômica, que gera a necessidade de uma coordenação acertada de esforços em vários níveis que evite a fragmentalidade ecossistêmica e o esvaziamento dos objetivos preservacionistas.

A região é detentora de uma riqueza inestimável, considerando-se que o ecossistema contém a maior biodiversidade do mundo, gerando a necessidade de se controlar todo o patrimônio genético daí oriundo. Além disso, a Amazônia possui vasta reserva de nióbio e uma das maiores reservas de água doce do mundo. 
A vasta floresta tropical possui a importante função de contribuir para a estabilização do clima em todo o continente, ou até mesmo, no mundo, por meio da regulação do regime natural de regulação de precipitações hídricas e armazenamento de carbono por suas grandes árvores.

Em razão das recentes queimadas e incêndios na Amazônia, noticiados em todo o mundo, e que chegou a gerar uma pequena, mas ruidosa crise diplomática com a França, o governo brasileiro respondeu com a edição do Decreto de ${ }^{\circ}$ 9.985, publicado em 23 de agosto de 2019, que autorizou o emprego das Forças Armadas para a Garantia da Lei e da Ordem e para ações subsidiárias nas áreas de fronteira, nas terras indígenas, em unidades federais de conservação ambiental e em outras áreas da Amazônia Legal, na hipótese de requerimento do Governador do respectivo Estado, com vistas a fortalecer as ações preventivas e repressivas contra delitos ambientais e o levantamento e combate a focos de incêndio.

Logo em seguida, como medida de fortalecimento das medidas editadas no Decreto $\mathrm{n}^{\circ}$ 9.985, foi editado o Decreto n ${ }^{\circ}$ 9.992, de 28 de agosto de 2019, que determinou a suspensão da permissão do emprego do fogo de que trata o Decreto n ${ }^{\circ}$ 2.661, de 8 de julho de 1998, no território nacional pelo prazo de sessenta (60) dias, salvo raras exceções ali previstas.

Para uma proteção efetiva dessa riqueza natural inestimável da região, vários outros instrumentos legais de comando e controle são colocados pelo ordenamento jurídico nacional à disposição dos cidadãos e do Estado, como a responsabilização penal, civil e administrativa, mas também, alguns instrumentos econômicos que visam incentivar financeiramente o desenvolvimento sustentável da região, estimulando a adoção de condutas mais adequadas do ponto de vista ambiental. E o presente trabalho visa justamente realizar uma análise crítica de uma das espécies desses instrumentos econômicos, a saber, os instrumentos tributários colocados em prática na região amazônica, com vistas ao desenvolvimento econômico aliado à preservação do bioma amazônico.

Portanto, objetiva-se verificar se as políticas públicas fiscais aplicadas para a região, por meio da atual configuração dos benefícios fiscais da Zona Franca de Manaus (ZFM), das atuais alíquotas e isenções do Imposto sobre a Propriedade de Veículos Automotores (IPVA) e da não instituição do Imposto sobre Circulação de Mercadorias e Prestação de Serviços (ICMS) ecológico no Estado do Amazonas, encontram-se em consonância com o direito fundamental ao meio ambiente ecologicamente equilibrado, bem como com os objetivos constitucionais de redução da desigualdade social/regional e da formação de uma sociedade mais justa e solidária.

\section{OS BENEFÍCIOS AMBIENTAIS E A NECESSIDADE GEOPOLÍTICA DE UMA POLÍTICA TRIBUTÁRIA AMBIENTAL PARA A REGIÃo AMAZÔNICA}

Para se ter uma ideia da relevância geopolítica da região amazônica, é quase um consenso de que ainda resta à humanidade somente três grandes eldorados naturais: a Antártida, que se encontra dividida entre as grandes potências; os fundos marinhos, que não se encontram regulamentados juridicamente e; o bioma transnacional da floresta amazônica, que está sob a soberania de vários estados nacionais.

Becker (2005) destaca que o seu povoamento e desenvolvimento foram fundados de acordo com o paradigma de relação sociedade-natureza, denominado de economia de fronteira, que enxergava o crescimento econômico como linear e infinito, baseado na contínua e ilimitada incorporação de terra e de recursos naturais, que caracteriza toda a formação latino-americana.

Sustenta, ainda, que no século XXI, é imperativo modificar esse padrão de desenvolvimento que alcançou o auge nas décadas de 1960 a 1980, baseado no uso predatório das fabulosas riquezas naturais da Amazônia. Sustar esse padrão de economia de fronteira revela-se, portanto, um imperativo internacional, nacional e também regional para que essa riqueza seja mais bem utilizada.

Na visão pragmática de Becker (2005), a floresta só deixará de ser destruída se tiver valor econômico para competir com a madeira, com a pecuária e com a soja. Mesmo com os grandes avanços na sua proteção, a questão de manter a sustentabilidade da floresta ainda não foi, como sabido, completamente solucionada. 
Para essa autora, não se pode olvidar que grande parte das florestas está localizada em áreas públicas e, por isso, são trunfos que estão sob o poder do Estado, que tem autoridade para delas dispor, segundo o interesse de toda a nação. E, por fim, encerra o seu raciocínio afirmando que a melhor proposta nacional para a região seria a promoção de uma verdadeira revolução científico-tecnológica para a Amazônia Florestal.

Para que se logre êxito na atribuição de valor econômico à floresta em pé, Borges e Merlin (2018) sustentam que os instrumentos da tributação ambiental podem oferecer, além da valorização do recurso natural, pela sua precificação e pela internalização dos custos das externalidades ambientais, um poderoso estímulo à mudança comportamental, no sentido de privilegiar a prevenção e a precaução. A lógica de imputação de custos aos poluidores, por um lado, desestimula a atividade prejudicial ao ambiente e, por outro, estimula o desenvolvimento sustentável.

Além disso, segundo os referidos autores, a operacionalização de uma tributação verde dá ensejo a uma verdadeira mudança de paradigmas, no que diz respeito à justiça fiscal. Isso porque o princípio da capacidade contributiva, princípio básico de um sistema tributário que pretende ser equitativo, cede vez ao princípio do poluidor-pagador, que busca concretizar a igualdade em outros termos: a equidade intrageracional e intergeracional.

Verificada as principais questões geopolíticas envolvidas no bioma amazônico e como a tributação voltada para a finalidade ecológica poderia colaborar para o desenvolvimento sustentável, necessário investigar se a região amazônica goza atualmente de uma política tributária ambiental bem planejada.

\section{A ZFM COMO INSTRUMENTO DE POLÍTICA TRIBUTÁRIA}

A ZFM foi instituída na década de 1950, pela Lei no 3.173/1957, em um período de forte apoio ao desenvolvimento econômico, concedido pelo governo Juscelino Kubitschek. Uma década depois o DecretoLei n 288/1967, definiu a região como uma área de livre comércio de importação e exportação e de incentivos fiscais especiais, estabelecida com a finalidade permitir o seu amplo desenvolvimento.

Em 1988, a Constituição da República Federativa do Brasil (CRFB) previu de forma expressa a ZFM no artigo 40 do Ato das Disposições Constitucionais Transitórias (ADCT), estabelecendo o seu prazo de duração e realçando a concessão de incentivos fiscais para a região como o principal instrumento de fomento ao desenvolvimento econômico, como pode ser observado no Art. 40 e Parágrafo Único.

\footnotetext{
Art. 40 - É mantida a Zona Franca de Manaus, com suas características de área livre de comércio, de exportação e importação, e de incentivos fiscais, pelo prazo de vinte e cinco anos, a partir da promulgação da Constituição.

Parágrafo único. Somente por lei federal podem ser modificados os critérios que disciplinaram ou venham a disciplinar a aprovação dos projetos na Zona Franca de Manaus (BRASIL, CRFB/1988, ADCT, Art. 40 e Parágrafo Único).
}

Após uma prorrogação de dez (10) anos em 2003, no ano de 2014 o seu prazo de duração foi prorrogado por mais surpreendentes cinquenta (50) anos, por meio da aprovação da Emenda Constitucional $n^{\circ}$ 83/2014, ou seja, o legislador entendeu que para a região atingir o nível de desenvolvimento desejável, os benefícios fiscais da ZFM deveriam perdurar até o ano de 2073, conforme prevê os Arts. 92 e 92-A, quando determina que "Art. 92. São acrescidos dez anos ao prazo fixado no art. 40 deste Ato das Disposições Constitucionais Transitórias. (EC no 42/2003)" e "Art. 92-A. São acrescidos 50 (cinquenta) anos ao prazo fixado pelo art. 92 deste Ato das Disposições Constitucionais Transitórias (EC no 83/2014) (BRASIL, ADCT, Art. 92 e Art. 92-A).

O fato da ZFM possuir previsão constitucional, contudo, não impede que os seus benefícios fiscais sejam constantemente reavaliados, com vistas a se verificar se as finalidades pretendidas pelo legislador por meio da sua instituição ainda se justificam ante o surgimento de efeitos extrafiscais muitas vezes não previstos. 
Vale a pena detalhar melhor o que se quer dizer com efeitos extrafiscais imprevistos. É sabido que a finalidade mais conhecida dos tributos é a arrecadação de recursos aos cofres públicos, no intuito de permitir que o Estado cumpra as suas atribuições. Essa finalidade é conhecida como fiscalidade. A extrafiscalidade, por sua vez, é a utilização dos tributos com objetivos que vão além da simples arrecadação de recursos (fiscalidade), por isso o prefixo "extra". Assim, no manuseio estatal das várias espécies de tributos, além da função arrecadatória de receitas para o Estado, podem ser também perseguidas funções regulatórias e indutoras do comportamento da sociedade como um todo ou de apenas um grupo de cidadãos.

Um exemplo clássico do que se está a dizer com efeitos extrafiscais não previstos seria o imposto sobre portas e janelas criado na França em 1798, que demonstra a imprevisibilidade de alguns efeitos gerados pela incidência de uma determinada política tributária. Segue interessante passagem do referido imposto na célebre obra Os Miseráveis, do escritor francês Victor Hugo, por meio de seu personagem Monsenhor Benvindo:

Há em França um milhão e trezentas e vinte mil casas de habitação de camponeses, as quais só têm três aberturas; um milhão e oitocentas e dezessete mil, que têm apenas duas, uma porta e uma janela; e, finalmente, trezentas e quarenta e seis mil cabanas, cuja única abertura é a porta. A causa disto é o denominado imposto das portas e janelas. Imaginai um montão de pessoas, uma família numerosa composta de velhos e crianças, vivendo juntas em cada um desses domicílios sem ar nem luz e pensai nas febres e epidemias a que isto pode dar origem (HUGO, 2013, p. 22).

Trata-se, como se percebe, de uma tentativa à época de tornar o sistema tributário de recolhimento do imposto francês sobre a propriedade mais simples, eficiente e, portanto, dotado de uma maior praticabilidade, mas que gerou graves efeitos nefastos à saúde das pessoas residentes dessas casas devido à insalubridade causada ao seu meio ambiente doméstico.

Moreira (2019) afirma que esse efeito inesperado é conhecido em todo o mundo como efeito cobra (cobra effect), e que esse termo se origina de um fato ocorrido na Índia do período colonial, em que os britânicos começaram a se preocupar com o alto número de cobras venenosas em Deli e resolveram oferecer uma recompensa para cada cobra morta. A estratégia acabou por se mostrar equivocada, porque as pessoas começaram a procriar cobras para obter renda e, com o fim do programa de recompensas, a população de cobras acabou aumentando ainda mais, pois os criadores as soltaram ante a falta do retorno financeiro almejado.

O referido autor ainda menciona outros exemplos do efeito cobra, como os efeitos nefastos sobre a arrecadação nacional gerados pelos incentivos tributários oriundos da guerra fiscal do ICMS e a desoneração da folha de pagamento, com a criação da Contribuição Previdenciária sobre a Receita Bruta (CPRB), que objetivava a criação de novos postos de emprego, mas que acabou não surtindo qualquer efeito relevante nesse sentido.

Especificamente em relação aos efeitos extrafiscais inesperados dos incentivos fiscais concedidos na ZFM, há forte crítica tecida por Scarpetta e Gonçalves (2016) quanto ao estímulo para a produção de motocicletas que, descrevem os autores, gerou um aumento expressivo e desordenado desse meio de transporte, com consequências nefastas para a saúde pública relacionadas ao aumento do número de acidentes, acarretando, além dessas tragédias pessoais, um forte impacto orçamentário decorrente da invalidez parcial, total ou a morte dos acidentados.

Não se pode olvidar ainda que as motocicletas são grandes causadoras de poluição sonora e do ar e que, por mais que o setor gere milhares de empregos, há outras formar de se buscar o desenvolvimento econômico, sem afetar tanto a saúde, o trânsito, as vidas humanas, o orçamento fiscal e o meio ambiente, como, por exemplo, por meio de incentivos ao transporte coletivo e subsídio aos combustíveis limpos. Fora da ZFM, o forte subsídio aos combustíveis e os incentivos fiscais aos automóveis no ano de 2013 com a redução do Imposto sobre Produtos Industrializados (IPI) e o subsídio da gasolina redundou em um montante duas vezes superior comparado ao que o poder público investiu em transporte público (GLOBO, 
2013), demonstrando o claro equívoco da política de mobilidade urbana.

Por meio do Decreto no 9.897/2019 o atual governo concedeu outro controvertido incentivo fiscal relacionado às bebidas açucaradas, reduzindo a carga tributária do IPI sobre a fabricação de concentrados de refrigerantes na ZFM.

Tal questão, de fato, merece ser amplamente debatida, pois se sabe que, segundo a Organização Mundial da Saúde (OMS), as bebidas adoçadas estão entre as principais causas de diabetes, obesidade e cáries de todo o mundo. Segundo (VALOR ECONÔMICO, 2019), tal medida de incentivo fiscal às bebidas ultraprocessadas e açucaradas da ZFM, instituída pelo Decreto 9.897/2019, coloca o Brasil na contramão do mundo na proteção ao direito à saúde e na instituição de um sugar tax.

Perceba-se que o agravamento da saúde da população representa uma maior deterioração das contas públicas devido à ampliação dos gastos com despesas da seguridade social, como remédios e hospitais públicos, auxílios decorrentes da invalidez permanente e temporária, verbas de assistência social, entre outros.

Por fim, outra crítica em relação à política tributária instituída pela ZFM está relacionada à concentração excessiva das atividades econômicas e industriais somente na região metropolitana de Manaus, gerando um povoamento pontual e deixando os demais municípios espalhados por todo o Estado do Amazonas em situação de vulnerabilidade econômica e abandono socioambiental (ATUAL AMAZONAS, 2019).

\section{O ICMS ECOLÓGICO NO ESTADO DO AMAZONAS}

O ICMS, de competência dos Estados e do Distrito Federal, está previsto na CRFB no artigo 155, inciso II e é reconhecido, em termos de arrecadação, como o principal tributo estadual, representando, em média, cerca de $90 \%$ da receita tributária dos Estados e 18,3\% do total que é arrecadado de tributos no país, conforme pode ser visualizado a seguir.

Art. 155. Compete aos Estados e ao Distrito Federal instituir impostos sobre: [...]

II - operações relativas à circulação de mercadorias e sobre prestações de serviços de transporte interestadual e intermunicipal e de comunicação, ainda que as operações e as prestações se iniciem no exterior; (BRASIL, CRFB/1988, Art. 155 e Inciso II).

$\mathrm{O}$ art. 158, inciso IV, da CRFB/1988 estabelece uma partilha de rendas do ICMS, aos municípios pertencentes àquele Estado, no percentual de $25 \%$ do produto da arrecadação. Além disso, assevera em seu parágrafo único que "as parcelas de receita pertencentes aos municípios, mencionadas no inciso IV, serão creditadas conforme os seguintes critérios:

Art. $158[\ldots]$

I - três quartos, no mínimo, na proporção do valor adicionado nas operações relativas à circulação de mercadorias e nas prestações de serviços, realizadas em seus territórios;

II - até um quarto, de acordo com o que dispuser lei estadual ou, no caso dos Territórios, lei federal (BRASIL, CRFB/1988, Art. 158, incisos I e II) (grifo nosso).

Ou seja, o texto constitucional estabelece que $25 \%$ (vinte e cinco por cento) do montante arrecadado com o ICMS de cada Estado pertence aos seus respectivos municípios, sendo que, no parágrafo único desse mesmo artigo, dispõe que até um quarto do pertencente aos municípios será distribuído conforme lei estadual, ou lei federal, no caso dos territórios nacionais. Logo, os Estados têm discricionariedade para determinar os critérios de distribuição dos 25\%, que na realidade representam 6,25\% do total arrecadado.

Assim, os estados da federação, tendo como pioneiro o Estado do Paraná no ano de 1991, começaram a criar leis estaduais próprias de redistribuição do ICMS, obedecendo aos limites percentuais estabelecidos na CRFB/1988, em busca de uma maior proteção ambiental por parte dos municípios e uma nova forma de compensá-los e até mesmo incentivá-los a manter grandes áreas de preservação ambiental em seus 
limites territoriais, mesmo com as limitações de uso do solo, o que gerava menor arrecadação de ICMS e menor recebimento de repasse, já que o critério se restringia ao recebimento de maior valor por aqueles que mais arrecadassem.

Segundo Pozzetti e Campos (2017), cada Estado, no entanto, criou critérios diferenciados segundo sua necessidade. Por exemplo, há Estados que adotam maior distribuição de recursos para o critério verde (proteção legal de reservas ambientais) enquanto outros priorizam o critério marrom (tratamento de lixo e esgotos sanitários). Portanto, a distribuição atende a uma fórmula, não é uma fatia fixa do recurso. Entre as variáveis estão o grau de conservação e a área protegida, assim, cada município recebe um valor de acordo com esses critérios pré-estabelecidos.

Em Minas Gerais e outros Estados, o ICMS Ecológico foi criado com objetivo ainda mais amplo do que uma mera gratificação aos Municípios por preservarem áreas de unidades de conservação. Slongo (2010) afirma que no Estado de Minas Gerais o ICMS Ecológico criou incentivos econômicos para governos locais investirem em resíduos sólidos e estações de tratamento de esgoto. Municípios recebem entre 50\% a 70\% para operem estações de tratamento de esgoto, com sistema adequado de disposição de resíduos sólidos. Esse incentivo econômico é combinado com o sistema de licenciamento, para obtê-lo os Municípios carecem ter a licença ambiental das estações de tratamento, das usinas de compostagem ou dos aterros sanitários.

No Estado do Pará, segundo Merlin e Oliveira (2016), o ICMS Ecológico ainda necessita ser aperfeiçoado, como tem sido ao longo dos anos, mas já gerou alguns benefícios ao bioma da Amazônia. Apesar de ainda apresentar graves problemas na implementação do seu sistema de gestão ambiental, inovações bastante positivas, como a conjugação do critério redução do desmatamento com a existência de cobertura vegetal mínima, a valorização do Cadastro Ambiental Rural (CAR) e a forma de ponderação no cômputo das Áreas Protegidas devem ser ressaltadas.

Segundo o jornal El Tiempo (2019), a Colômbia, por sua vez, que faz parte da Amazônia Internacional, está em vias de aprofundar seus iniciativos tributários voltados para as finalidades ambientais com medidas fiscais de incentivos bem similares às buscadas pelo ICMS ecológico.

Para Derani (2013), o sucesso do instrumento depende da boa administração dos recursos repassados pelo ICMS Ecológico, devendo o Município investir não apenas em obras públicas e sociais, mas em projetos ambientais que valorizem as áreas naturais protegidas, incluindo Reservas Particulares do Patrimônio Natural (RPPN) e outras Unidades de Conservação pertencentes às três esferas federais, pelo que será financeiramente compensado, pois quanto melhor a qualidade da gestão ambiental municipal maior o índice de participação nos recursos oriundos daquele imposto.

Um bom exemplo, citado pela autora, pode ser encontrado em São Miguel Arcanjo, no interior de São Paulo. O município possui aproximadamente $20 \%$ de seu território ocupado por Unidades de Conservação havendo recebido, entre os anos de 2006 a 2010, cerca de R\$ 2 milhões a título de ICMS Ecológico, recurso aplicado em ações de educação ambiental, na construção de novos pontos de coleta de lixo na zona rural, bem como na coleta seletiva da zona urbana, conforme estabelece a Lei Municipal no 2.303/2000 .

Não obstante todas as experiências positivas acima narradas, o Estado do Amazonas ainda não instituiu o ICMS Ecológico. Não há justificativas para tal omissão legislativa, não somente pela importância das suas riquezas naturais, mas também pela questão socioeconômica, já que a criação do ICMS Verde no Amazonas beneficiaria diretamente as dezenas de municípios abandonados do interior do estado com o aumento de repasse em detrimento do rico município de Manaus.

Aqui é importante frisar que Manaus, por ser simultaneamente a capital do Estado e o único polo industrial da ZFM, possui uma arrecadação desproporcional de ICMS em relação ao restante do Estado e representa cerca de $85 \%$ dos recursos, justamente por ser o município onde a quase totalidade de circulação de mercadorias e serviços de transporte e comunicação ocorre (ATUAL AMAZONAS, ${ }^{2019)}$.

Vale pontuar que, segundo Tupiassu (2006), a redistribuição de receitas é algo totalmente previsto e

1 Para outras informações e exemplos, ver o sítio eletrônico disponível em: < http://www.icmsecologico.org.br>. 
inerente ao próprio funcionamento do ICMS Verde. A finalidade ecológica desse instrumento tributário é, ao mesmo tempo, incentivar a preservação ambiental e gerar recursos para preservar e recuperar áreas, criando emprego e renda, reduzindo assim a desigualdade regional.

A perspectiva é que a discussão ganhe força com o apoio da sociedade civil, para que o Amazonas abra espaço para a discussão sobre o ICMS Ecológico, criando e regulamentando sua normativa para, assim, passar a fazer parte do rol dos estados que incentivam seus municípios para a boa gestão ambiental de seus recursos naturais.

\section{O IPVA NO ESTADO DO AMAZONAS}

Antes de se analisar a política tributária do Estado do Amazonas para o IPVA, necessário se fazer algumas considerações de caráter propedêutico. O IPVA, apesar de seu inegável caráter fiscal (função arrecadadora), possui, desde a promulgação da Emenda Constitucional no 42 de 2003, uma abertura franqueada no próprio texto constitucional para o exercício de uma potente função extrafiscal de cunho ecológico, ainda pouco utilizada.

Desde 2003, portanto, há o permissivo constitucional para os Estados e o Distrito Federal implementarem a extrafiscalidade (com finalidade ambiental ou social) do IPVA mediante a fixação de alíquotas diferenciadas em razão do tipo e da utilização do veículo, conforme autorizado pelo art. 155 , $\int 6^{\circ}$, II, $\mathrm{CRFB} / 1988^{2}$.

Assim, não é difícil constatar que as leis estaduais instituidoras do referido imposto poderão implementar uma extrafiscalidade com viés social, prevendo alíquotas maiores para veículos mais luxuosos e que sejam utilizados para uso particular, e alíquotas menores para aqueles modelos mais simples e que sejam utilizados para o exercício de algum trabalho ou profissão.

E a extrafiscalidade ambiental do IPVA, por sua vez, pode ser efetivada não somente com a progressividade de alíquotas para os veículos mais poluidores, mas também, com incentivos fiscais para os automóveis com menor pegada ecológica. O STF já se manifestou sobre o tema, sendo válido transcrever a seguinte ementa de acórdão que considerou constitucional essa finalidade tributária regulatória, por meio da diferenciação de alíquotas com base na destinação (utilização) dada ao veículo:

IPVA - ALÍQUOTAS DIFERENCIADAS. Não implica ofensa à Constituição Federal o estabelecimento de alíquotas diferenciadas conforme a destinação do veículo automotor. Precedentes: Agravos Regimentais nos Recursos Extraordinários n 414.259/MG e no 466.480/MG, ambos relatados na Segunda Turma, pelo Ministro Eros Grau; e Agravo Regimental no Agravo de Instrumento n ${ }^{\circ}$ 167.777/SP, Segunda Turma, de minha relatoria, entre outros. IPVA - AUTOMÓVEIS USADOS VALOR VENAL - DEFINIÇÃO PELO PODER EXECUTIVO. Prevendo a lei a incidência da alíquota do Imposto sobre Propriedade de Veículos Automotores - IPVA sobre o valor venal do veículo, não conflita com a Carta da República a remessa da definição do quantitativo ao Executivo. (RE 424991 AgR/MG - MINAS GERAIS AG.REG. NO RECURSO EXTRAORDINÁRIO - Relator(a): Min. MARCO AURÉLIO - Julgamento:13/09/2011 - Órgão Julgador: Primeira Turma).

Para se ter uma ideia da relevância do tema, nos municípios brasileiros com mais de quinhentos mil (500.000) habitantes, a causa mais decisiva para os altos níveis de poluição do ar é justamente a poluição gerada pelos veículos automotivos. ${ }^{3}$ No Brasil, a opção pelo veículo automotor individual torna-se ainda mais fortalecida ante a inexistência de um transporte público de qualidade que ofereça uma alternativa ao cidadão das diversas municipalidades.

\footnotetext{
${ }^{2}$ Art. 155, [...] \ $6^{\circ} \mathrm{O}$ imposto previsto no inciso III: (Incluído pela Emenda Constitucional no 42, de 19.12.2003) [...] II - poderá ter alíquotas diferenciadas em função do tipo e utilização. (Incluído pela Emenda Constitucional no 42, de 19.12.2003).

3 IBGE. Perfil dos municípios brasileiros - Meio ambiente, 2002. Disponível em: <www.ibge.gov.br/home/estatistica/econo$\mathrm{mia} /$ perfilmunic/meio_ambiente_2002/meio_ambiente2002.pdf > . Acesso em: 10 de set. de 2019.
} 
O IPVA dotado com uma função ambiental estaria em consonância com o espírito da Lei Federal $\mathrm{n}^{\circ} 8.723$ de outubro de 1993, que trata sobre o controle da emissão de poluentes por veículos e obriga os estados a tomarem as providências necessárias para reduzir os níveis de emissão de monóxido de carbono e outros compostos poluentes nos veículos comercializados no país. Ademais, atenderia à Lei no 10.203 , de 22 de fevereiro de 2001, que prevê o incentivo ao uso de combustíveis automotivos classificados pelo Instituto Brasileiro do Meio Ambiente e dos Recursos Naturais Renováveis (IBAMA) como de baixo potencial poluidor.

No RE no 236.931 (D.J. 29.10.99), o STF entendeu que tal mecanismo tributário não constitui aplicação da técnica da progressividade ou da capacidade econômica, mas tão somente guarda conformidade com uma política extrafiscal para o incentivo de tecnologias limpas (GODOI e MOREIRA, 2002). Ou seja, quando se trata de quantificar tributos com finalidades extrafiscais, a capacidade contributiva do proprietário do veículo automotor não é o único critério a ser considerado.

Nessa ordem de ideias, há que se ressaltar que todos os bens, sejam móveis ou imóveis, devem cumprir a sua função social, em homenagem ao princípio da função social da propriedade. Nessa esteira, assim como já há a consagração da progressividade extrafiscal de alíquotas para o Imposto Predial e Territorial Urbano (IPTU) e para o Imposto sobre a Propriedade Territorial Rural (ITR), não há mais razões jurídicas ou fáticas para não considerar a utilização dessa técnica extrafiscal para o IPVA.

No Brasil, o IPVA possui alíquotas que variam entre $0,5 \%$ e $4 \%$ incidentes sobre o valor de mercado (venal) do veículo. Mas há notícias de que alguns Estados da federação já isentaram os Veículos Elétricos (DOMINGUES, 2012), assim como todo o Japão (ÁSIA COMENTADA, 2019).

Tais iniciativas se mostram importantes e estimulam os consumidores a adotar as novas tecnologias menos poluentes, deixando de lado os veículos automotores que se utilizam de toda uma produção altamente poluente baseada em combustíveis fósseis. Contudo, na contramão das iniciativas ambientais para o IPVA, há notícia de que vários estados da federação concedem isenção justamente para os veículos mais antigos (de 10 a 20 anos), que, obviamente, emitem muito mais gases poluentes na atmosfera, numa demonstração de desconsideração das políticas tributárias com o equilíbrio do meio ambiente (DOS SANTOS, BASSOLI, 2009).

E um desses Estados que, infelizmente, ainda não possui qualquer política tributária ambiental para o IPVA é o Amazonas. Segundo o art. 4, VI, do Regulamento do IPVA (RIPVA - Decreto n 26.428/2006) do Estado, são isentos, dentre outros, os veículos automotores com mais de 15 (quinze) anos de uso, a contar do ano de seu primeiro licenciamento no órgão público competente. A legislação do Estado do Amazonas também não apresenta qualquer variação de alíquotas de IPVA com a finalidade mais marcadamente ambiental, como, por exemplo, tipo de combustível utilizado ou nível de poluição gerado pelo veículo.

\section{CONSIDERAÇÕES FINAIS}

De tudo o que foi exposto, percebe-se que, diante de todos os instrumentos jurídicos colocados à disposição pelo ordenamento jurídico para o Estado brasileiro perseguir o desenvolvimento socioambiental de forma sustentável na região amazônica, os instrumentos econômicos se destacam pela eficácia de induzir os comportamentos sem a necessidade de uma estrutura cara e pesada como exigem os instrumentos de responsabilização típicos de comando e controle.

Dentre os instrumentos econômicos, foi analisada a real necessidade de se aprofundar a utilização dos instrumentos tributários, onde foi avaliada a política tributária implementada em diferentes níveis para auxiliar a preservação das inestimáveis riquezas naturais da Amazônia e manter um desenvolvimento socioambiental que fortaleça o Brasil no contexto geopolítico que envolve o bioma ali existente.

Com esse intuito, foram avaliados, primeiramente, os incentivos fiscais promovidos por meio Zona Franca de Manaus (ZFM), momento em que se constatou que há uma real necessidade de se reavaliar os referidos benefícios, porquanto estão a concentrar o povoamento e as atividades econômicas na região metropolitana de Manaus, promovem hábitos alimentares não saudáveis ao reduzir a carga tributária sobre as 
bebidas açucaradas e proliferam de forma desordenada o uso de motocicletas por todo o país, em detrimento do transporte coletivo, afetando a saúde, a vida das vítimas de acidentes e provocando o caos na mobilidade urbana.

A despeito das experiências positivas com o ICMS Ecológico em vários Estados da federação, inclusive situados na Amazônia Legal, verificou-se que o Estado do Amazonas ainda não implementou tal política tributária ambiental. Tal omissão, oriunda de um Estado que possui a maior reserva florestal, hídrica e de biodiversidade do país, revela-se injustificável e, como vimos, afeta não somente o meio ambiente, mas também o desenvolvimento socioeconômico dos demais municípios afastados da região metropolitana de Manaus, ante o potencial caráter redistributivo dessa modalidade de ICMS verde.

Por fim, foi analisada a política tributária do IPVA do Estado do Amazonas, ante a possibilidade franqueada pela Constituição da República de se instituir a extrafiscalidade ambiental para esse imposto, por meio da fixação de alíquotas diferenciadas em razão do tipo e utilização do veículo. Apesar desse estímulo conferido pela própria Carta Federal, o Estado do Amazonas não se preocupou em estabelecer a progressividade de alíquotas para os veículos mais poluidores, e tampouco conferir incentivos fiscais para os automóveis com menor pegada ecológica. Os veículos elétricos e os movidos à gasolina, portanto, são tratados da mesma forma pela legislação tributária estadual, sem qualquer estímulo à aquisição de veículos com base em critérios ambientais.

Dessa forma, o que se constata é que esse verdadeiro eldorado natural amazônico não conta com uma política tributária adequada voltada para o seu desenvolvimento sustentável, exigindo que o Estado brasileiro, em seus diferentes níveis, dependa demasiadamente dos demais instrumentos econômicos, e, sobretudo, da cara estrutura estatal de comando e controle para responsabilização dos agentes econômicos causadores de danos ambientais.

Em uma época em que rondam ameaças de internacionalização da floresta amazônica, uma melhor gestão ambiental, por meio dos instrumentos tributários, seria fundamental para o fortalecimento da soberania afirmativa do Estado brasileiro naquela região.

\section{REFERÊNCIAS}

AMAZONAS. Decreto $\mathbf{n}^{\mathbf{0}} \mathbf{2 6 . 4 2 8}$, de 29 de dezembro de 2006. Aprova o regulamento do Imposto sobre a Propriedade de Veículo Automotor (RIPVA). Disponível em: <http://online.sefaz.am.gov.br/silt/Normas/Legisla\%C3\%A7\%C3\%A30\%20Estadual/Decreto\%20Estadual/Ano\%202006/Ar-

quivo/DE_26428_06.htm> Acesso em: 13 de set. de 2016.

ÁSIA COMENTADA. Veículos menos poluentes com reduções fiscais no Japão. Disponível em: <https://www.asiacomentada.com.br/2019/01/veculos-menos-poluentes-com-redues-fiscais-no-japo/> Acesso em: 13 de set. de 2019.

ATUAL AMAZONAS. Cinco municípios do Amazonas concentram dinheiro federal e estadual. Disponível em: <https://amazonasatual.com.br/cinco-municipios-do-amazonas-concentram-dinheiro-federal-e-estadual/> Acesso em: 05 de set. de 2019.

BECKER, Bertha K. Geopolítica da Amazônia. Estud. av., São Paulo, v. 19, n. 53, p. 71-86, Apr. 2005. BRASIL. Constituição da República Federativa do Brasil. Brasília: Senado Federal, 1988. Disponível em: <http://www.planalto.gov.br/ccivil_03/constituicao/_ConstituiçaoCompilado.htm>. Acesso em: 13 set. 2019.

. Decreto de $\mathbf{n}^{\circ} \mathbf{9 . 9 8 5}$, de 23 de agosto de 2019. Autoriza o emprego das Forças Armadas para a Garantia da Lei e da Ordem e para ações subsidiárias nas áreas de fronteira, nas terras indígenas, em unidades federais de conservação ambiental e em outras áreas da Amazônia Legal na hipótese de requerimento do Governador do respectivo Estado. Disponível em: http://www.planalto.gov.br/ccivil_03/_ato2019-2022/ 2019/decreto/D9985.htm.

. Decreto $\mathrm{n}^{\circ}$ 9.992, de 28 de agosto de 2019. Determina a suspensão da permissão do emprego do fogo de que trata o Decreto $\mathrm{n}^{\mathrm{o}}$ 2.661, de 8 de julho de 1998, no território nacional pelo prazo de sessenta 
dias. Disponível em: http://www.planalto.gov.br/ccivil_03/_Ato2019-2022/2019/Decreto/D9992.htm.

Decreto $\mathrm{n}^{\circ}$ 2.661, Decreto $\mathrm{n}^{\circ}$ 2.661, de 8 de julho de 1998. Regulamenta o parágrafo único do art. 27 da Lei $\mathrm{n}^{\circ}$ 4.771, de 15 de setembro de 1965 (código florestal), mediante o estabelecimento de normas de precaução relativas ao emprego do fogo em práticas agropastoris e florestais, e dá outras providências. Disponível em: http://www.planalto.gov.br/ccivil_03/decreto/D2661.htm.

Lei $\mathbf{n}^{\mathbf{0}}$ 3.173, de 6 de junho de 1957. Cria uma zona franca na cidade de Manaus, capital do Estado do Amazonas, e dá outras providências (Revogado). Disponível em: http://www.planalto.gov.br/ccivil_03/leis/1950-1969/L3173.htm.

Decreto-Lei $\mathbf{n}^{\mathbf{0}} \mathbf{2 8 8}$, de 28 de fevereiro, de 1967. Altera as disposições da Lei número 3.173 de 6 de junho de 1957 e regula a Zona Franca de Manaus. Disponível em: http://www.planalto.gov.br/ccivil_03/Decreto-Lei/Del0288.htm.

Decreto $\mathbf{n}^{\circ}$ 9.897, de 1 de julho de 2019. Altera a Tabela de Incidência do Imposto sobre Produtos Industrializados - TIPI, aprovada pelo Decreto $\mathrm{n}^{\circ}$ 8.950, de 29 de dezembro de 2016. Disponível em: http://www.planalto.gov.br/ccivil_03/_ato2019-2022/2019/decreto/D9897.htm.

Lei Federal $\mathbf{n}^{\circ} \mathbf{8 . 7 2 3}$, de outubro de 1993. Dispõe sobre a redução de emissão de poluentes por veículos automotores e dá outras providências. Disponível em: http://www.planalto.gov.br/ccivil_03/LEIS /L8723.htm.

Lei $n^{\circ}$ 10.203, de 22 de fevereiro de 2001. Dá nova redação aos arts. $9^{\circ}$ e 12 da Lei no 8.723 , de 28 de outubro de 1993, que dispõe sobre a redução de emissão de poluentes por veículos automotores, e dá outras providências. Disponível em: http://www.planalto.gov.br/ccivil_03/LEIS/LEIS_2001/L10203. htm.

STF - no RE: 424991, Relator: Min. MARCO AURÉLIO, Data de Julgamento: 13/09/2011, Primeira Turma, Data de Publicação: DJe-198 DIVULG 13-10-2011 PUBLIC 14-10-2011 EMENT VOL02607-04 PP-00656. Disponível em: https://stf.jusbrasil.com.br/jurisprudencia/20621249/agreg-no-recur so-extraordinario-re-424991-mg-stf.

STF no RE 466480, Relator(a): Min. EROS GRAU, julgado em 14/09/2006, publicado em DJ 28/09/2006 PP-00075. Disponível em: http://www.stf.jus.br/portal/jurisprudencia/visualizarEmenta.asp? s1 $=000158785 \&$ base $=$ baseMonocraticas.

BORGES, Felipe Garcia Lisboa; MERLIN, Lise Vieira da Costa Tupiassu. A (In) Viabilidade da Reforma Fiscal Verde no Brasil. Veredas do Direito: Direito Ambiental e Desenvolvimento Sustentável, Belo Horizonte, v. 15, n. 33, p. 347-375, dez. 2018.

DERANI, Cristiane; SOUZA, Kelly Schaper Soriano de. Instrumentos Econômicos na Política Nacional do Meio Ambiente: por uma economia ecológica. Veredas do Direito: Direito Ambiental e Desenvolvimento Sustentável, Belo Horizonte, v. 10, n. 19, p. 247, set. 2013.

DOMINGUES, José Marcos. Tributação, Políticas Públicas e Eficiência Energética: Caso do Veículo Elétrico. Revista Tributária e de Finanças Públicas, vol. 107, p. 207, Nov. 2012

DOS SANTOS, Althair Ferreira; BASSOLI, Marlene Kempfer. Incentivos por meio de alíquotas seletivas de IPVA para veículos automotores movidos a combustível de menor impacto ambiental. Revista De Direito Público, Londrina, V, 4, N. 3, P. 136-155, set./dez. 2009, p. 154.

EL TIEMPO. Impuestos verdes y pensiones, las nuevas leyes económicas del gobierno. Disponível em: <https://www.eltiempo.com/economia/sectores/proyectos-y-reformas-economicas-del-gobierno-qu e-se-vienen-393876> Acesso em: 15 de set. de 2019.

GLOBO. Incentivos e subsídios para carros somam quase o dobro do investido em transporte coletivo em 2013. Disponível em: <http://oglobo.globo.com/economia/incentivos-subsidios-carros-somam-quase-dobro-do-investido-em-transportecoletivo-em-2013- 4439996> Acesso em: 05 de set. de 2019. GODOI, Marciano Seabra de; MOREIRA, Gilberto Ayres. Princípio da progressividade. In: GODOI, Marciano Seabra de (coord). Sistema Tributário Nacional na Jurisprudência do STF. São Paulo; Dialética, 2002, pp. 316-317.

HUGO, Victor. Os miseráveis. Tradução de Francisco Ferreira da Silva Vieira. Centaur Editions, 2013, 
p.22.

IBGE. Perfil dos municípios brasileiros - Meio ambiente, 2002. Disponível em: <www.ibge.gov.br/ho $\mathrm{me} /$ estatistica/economia/perfilmunic/meio_ambiente_2002/meio_ambiente2002.pdf>. Acesso em: 10 de set. de 2019.

MERLIN, Lise Vieira da Costa Tupiassu; OLIVEIRA, Adriano Carvalho. ICMS verde para a redução do desmatamento amazônico: estudo sobre uma experiência recente. Veredas do Direito: Direito Ambiental e Desenvolvimento Sustentável, Belo Horizonte, v. 13, n. 25, p. 277-306, mai. 2016.

MOREIRA, Bernardo Motta. A avaliação de impacto da lei tributária no Brasil. In: A tributação na sociedade moderna: economia digital, compliance tributária, direitos sociais e reforma tributária. (Org.) DA MATA, Juselder Cordeiro; BERNARDES, Flávio Couto; LOBATO, Valter de Souza. Belo Horizonte. Arraes Editores, 2019, p. 159.

POZZETTI, Valmir César; CAMPOS, Jalil Fraxe. ICMS Ecológico: um desafio à sustentabilidade econômico ambiental no Amazonas. Revista Jurídica. Vol. 02, nº. 47, Curitiba, 2017, p. 267.

SCARPETTA, Juliano; GONÇALVES, Oksandro Osdival. Incentivos fiscais e o aumento de custos da saúde pública: o caso da "epidemia" de motocicletas no brasil. Veredas do Direito: Direito Ambiental e Desenvolvimento Sustentável. Belo Horizonte, v. 12, n. 24, p. 227-255, jan. 2016.

SLONGO, Daniela Roberta. Considerações Gerais Sobre o Pagamento Por Serviços Ambientais Como um Instrumento Econômico para a Conservação das Águas, Florestas e da Biodiversidade. In: GALLI, Alessandra (coord.). Direito Socioambiental. Curitiba: Jaruá, 2010. vol.02, p. 181.

TUPIASSU, Lise Vieira da Costa. Tributação Ambiental. Rio de Janeiro: Renovar, 2006, p. 200.

VALOR ECONÔMICO. O Brasil na contramão e os incentivos fiscais às bebidas açucaradas. Disponível em: < https://www.valor.com.br/legislacao/fio-da-meada/6340567/o-brasil-na-contramao-e-os-in centivos-fiscais-bebidas-acucaradas >. Acesso em: 10 de set. de 2019. 